\title{
Relation between serum uric acid and lower limb blood flow in patients with chronic heart failure
}

\author{
Stefan D Anker, Francisco Leyva, Philip A Poole-Wilson, Wolfgang J Kox, \\ John C Stevenson, Andrew J S Coats
}

Department of Cardiac Medicine, Imperial College School of Medicine at the National Heart and Lung Institute,

London, United Kingdom $S$ D Anker F Leyva

P A Poole-Wilson

A J S Coats

Wynn Department of Metabolic Medicine, Imperial College School of Medicine at the National Heart and Lung Institute,

London, United Kingdom

J C Stevenson

Department of

Anaesthesiology and

Intensive Care

Medicine, University

Hospital Charité,

Humboldt University

Berlin, Berlin,

Germany

W J Kox

Correspondence to:

Dr Francisco Leyva, Wynn
Department of Metabolic

Medicine, Imperial College

School of Medicine at the

National Heart and Lung

Institute, 21 Wellington

Institute, 21 Wellington

United Kingdom.

Accepted for publication

31 January 1997

\begin{abstract}
Objective-To determine whether lower limb blood flow is related to serum uric acid concentrations in patients with chronic heart failure, taking into account the hyperuricaemic effects of diuretic treatment and insulin resistance.
\end{abstract}

Design-Lower limb blood flow was measured at rest and after maximum exercise followed by a five minute period of ischaemia (maximum blood flow) using strain gauge venous occlusion plethysmography. All patients underwent a metabolic assessment, which included an intravenous glucose tolerance test (IVGTT)-to obtain an index of insulin sensitivity-and measurement of serum uric acid.

Setting-University and hospital departments specialising in cardiology and metabolic medicine.

Subjects-22 patients with chronic heart failure.

Results-Mean (SEM) resting and maximum blood flow values were $2.87(0.23)$ and $24.00(1.83) \mathrm{ml} / 100 \mathrm{ml} / \mathrm{min}$, respectively. Patients in the upper tertile of serum uric acid had lower maximum blood flow than those in the lowest tertile $(15.6(2 \cdot 2) v 31.0(2 \cdot 1) \mathrm{ml} / 100 \mathrm{ml} / \mathrm{min}, P=$ $0 \cdot 003)$. Serum uric acid correlated with maximum blood flow $(r=-0.86, P<$ $0 \cdot 001$ ), but not with resting blood flow. In stepwise regression analysis, uric acid emerged as the only predictor of maximum blood flow (standardised coefficient $=-0.83(\mathbf{P}<0.001), R^{2}=0.68(P<$ $0.001)$ ), independently of diuretic dose, age, body mass index, plasma creatinine, fasting and IVGTT glucose and insulin, insulin sensitivity, maximum oxygen uptake and exercise time during the treadmill exercise test, and alcohol intake. Conclusions-There is a strong inverse relation between serum uric acid concentrations and maximum leg blood flow in patients with chronic heart failure. Further studies are needed to determine whether serum uric acid can be used as an index of vascular function in cardiovascular diseases.

(Heart 1997;78:39-43)

Keywords: uric acid; xanthine oxidase; blood flow; chronic heart failure
In healthy individuals, lower limb blood flow increases by as much as 20 -fold during exercise. ${ }^{1}$ This response is severely compromised in patients with chronic heart failure ${ }^{2-4}$ and partly accounts for the fatigue and impaired exercise tolerance experienced by patients with this condition. ${ }^{5}$

No unifying pathophysiological mechanism has been proposed for the common association of hyperuricaemia with cardiovascular disease and its risk factors. The observation that interruption of arterial flow to the limbs results in an increase in serum uric acid ${ }^{6}$ suggests that disturbances in blood flow may be related to hyperuricaemia. Lower limb ischaemia, as assessed by the presence of intermittent claudication or by a reactive hyperaemia test, is related to serum uric acid concentrations. ${ }^{7}$ In the heart, increases in serum uric acid have been observed in the coronary sinus following balloon inflations during coronary angioplasty ${ }^{89}$ and during coronary artery bypass operations. ${ }^{10}$ These findings suggest a link between serum uric acid and impairment of regional blood flow.

On this basis, we hypothesised that in chronic heart failure, serum uric acid concentrations might be inversely related to lower limb blood flow. In testing this hypothesis, it is necessary to consider that chronic heart failure is an insulin resistant, hyperinsulinaemic state, ${ }^{11}$ and that diuretic treatment, ${ }^{12}$ adiposity, ${ }^{13}$ plasma insulin, and insulin resistance ${ }^{14} 15$ are also correlated with serum uric acid concentrations.

\section{Methods}

Twenty two patients with chronic heart failure due to coronary heart disease $(n=12)$ or idiopathic dilated cardiomyopathy $(n=10)$ were included in the study. In the chronic heart failure group, 18 patients were taking angiotensin converting enzyme inhibitors, 17 were taking loop diuretics, nine were taking thiazide diuretics, and nine were taking potassium sparing diuretics, either alone or in combination. No patients were taking hypouricaemic drugs. All patients had been in chronic heart failure for more than three months. Patients with chronic lung disease, haemodynamically important valve disease, neuromuscular disorders, myocardial infarction in the preceding three months, severe renal failure, symptomatic peripheral vascular disease, or excessive alcohol intake were 
excluded from the study. All patients gave written informed consent, and the protocol was approved by the local ethics committee.

\section{METABOLIC STUDY}

Metabolic studies were carried out in our metabolic day ward as described previously. ${ }^{11}$ Briefly, blood samples were taken for measurement of fasting plasma glucose and insulin concentrations and serum uric acid. Participants then underwent an intravenous glucose tolerance test (IVGTT) $(0.5 \mathrm{~g} / \mathrm{kg}$ body weight dextrose given as a $\mathbf{5 0 \%}$ solution) with sampling for plasma glucose and insulin at 3, $5,7,10,15,20,30,45,60,90,120,150$, and 180 minutes after injection of the glucose solution. All metabolic studies were carried out in the morning and all physical measurements in the afternoon of the day of assessment.

FUNCTIONAL CAPACITY

All patients were encouraged to exercise to exhaustion while undergoing a symptom limited treadmill exercise test. A standard Bruce protocol was employed, with the addition of a stage " 0 " (three minutes of exercise at one mile per hour with a gradient of $5 \%$ ) for patients with chronic heart failure. A respiratory mass spectrometer (Amis 2000, Odense, Denmark) connected to by a one way valve was used for measurement of maximum oxygen consumption using a standard inert gas dilution technique. Left ventricular ejection fraction was estimated by radionuclide ventriculography using a stannous fluoride red cell labelling agent, a bolus injection of radiolabelled ${ }^{99} \mathrm{Tc}$, and gamma camera imaging.

\section{LEG BLOOD FLOW}

Leg blood flow in the right leg was determined using a mercury-in-Silastic strain gauge venous occlusion plethysmography. ${ }^{16}$ Patients were rested in the supine position for at least 10 minutes, with the leg slightly elevated. A cuff placed around the right thigh was connected to a rapid inflation pump (Hokanson, Bellevue, USA). The strain gauge was placed at the largest part of the calf and connected to a plethysmograph (EC4, Hokanson, Bellevue, USA). Measurement of resting blood flow

Table 1 Characteristics of study group

\begin{tabular}{lc}
\hline Age (years) & $62 \cdot 3(2 \cdot 7)$ \\
Body mass index $\left(\mathrm{kg} / \mathrm{m}^{2}\right)$ & $23 \cdot 0(0 \cdot 6)$ \\
Systolic blood pressure $(\mathrm{mm} \mathrm{Hg})$ & $109 \cdot 2(4 \cdot 0)$ \\
Diastolic blood pressure $(\mathrm{mm} \mathrm{Hg})$ & $67 \cdot 1(2 \cdot 5)$ \\
Creatinine $(\mu \mathrm{mol} / \mathrm{l})$ & $129 \cdot 6(9 \cdot 4)$ \\
Uric acid ( $\mu \mathrm{mol} / \mathrm{l})$ & $527 \cdot 2(37 \cdot 8)$ \\
Fasting glucose $(\mu \mathrm{mol} / \mathrm{l})$ & $6 \cdot 1(0 \cdot 6)$ \\
IVGTT glucose $(\mathrm{mmol} / \mathrm{min})$ & $595 \cdot 1(50 \cdot 8)$ \\
Fasting insulin $(\mathrm{pmol} / \mathrm{m})$ & $38 \cdot 8(-6 \cdot 01,7 \cdot 10)$ \\
IVGTT insulin $\left(\mathrm{pmol} / 1 / 1 \cdot 10^{-4}\right)$ & $1 \cdot 67(-0 \cdot 22,0 \cdot 26)$ \\
Insulin sensitivity $\left(10^{5} / \mathrm{min} /[\mathrm{pmol} / \mathrm{l}]\right)$ & $1 \cdot 71(-0 \cdot 33,0 \cdot 36)$ \\
Diuretic dose $(\mathrm{mg})$ & $88 \cdot 2(12 \cdot 8)$ \\
Resting blood flow $(\mathrm{ml} / 100 \mathrm{ml} / \mathrm{min})$ & $2 \cdot 87(0 \cdot 23)$ \\
Maximum blood flow $(\mathrm{ml} / 100 \mathrm{ml} / \mathrm{min})$ & $24 \cdot 00(1 \cdot 84)$ \\
Left ventricular ejection fraction $(\%)$ & $25 \cdot 8(3 \cdot 4)$ \\
NYHA class & 1 \\
I & 8 \\
II & 11 \\
III & 2 \\
IV &
\end{tabular}

Results are expressed as mean (SEM), except for insulin concentrations and insulin sensitivity, which are expressed as mean (-SEM, + SEM).

IVGTT, intravenous glucose tolerance test; NYHA, New York Heart Association. were taken after inflation of the cuff to $40 \mathrm{~mm} \mathrm{Hg}$. A further measurement of leg blood flow was obtained immediately after a maximal exercise test (described above) followed by a five minute period of ischaemia (to achieve maximum vasodilator capacity). This was achieved by inflating the cuff to suprasystolic pressure $(30 \mathrm{~mm} \mathrm{Hg}$ above the systolic blood pressure measured at the peak of exercise) for five minutes. The time period between finishing the exercise test and this blood flow measurement did not exceed six minutes (one minute to the start of cuff inflation and five minutes for ischaemia). Blood flow was measured at five seconds, 15 seconds, and then every 10 seconds until the flow decreased. The highest flow results were considered to be the maximum leg blood flow. All results for leg blood flow are expressed as millilitres of blood flow per $100 \mathrm{ml}$ tissue per minute $(\mathrm{ml} / 100$ $\mathrm{ml} / \mathrm{min}$ ).

\section{LABORATORY DETERMINATIONS}

Plasma glucose was determined on the same day by glucose oxidase procedure using aminophenazone. ${ }^{17}$ Plasma insulin concentrations were measured on samples stored at $-20^{\circ} \mathrm{C}$ using the radioimmunoassay procedure. ${ }^{18}$ Serum uric acid was determined by the uricase-peroxidase method $^{19}$ using a Cobas Mira discrete analyser (Roche, Switzerland). Within and between batch precision was monitored throughout the study using frozen plasma and serum pools and commercially available freeze dried sera, and by participation in national quality assurance schemes.

\section{DATA ANALYSES}

Fasting plasma concentrations of glucose and insulin were taken as the mean of the two pretest samples. Incremental areas under the IVGTT concentration profiles were calculated using the trapezium rule. In the derivation of mean values, insulin measures were logarithmically transformed and insulin sensitivity square root transformed. The latter-inversely related to insulin resistance-was assessed using the minimal model approach. ${ }^{20}$ Univariate Pearson correlation coefficients were derived. Stepwise multiple linear regression analyses adopted a tolerance of 0.01 for entry into the models. Group differences were assessed using the Mann-Whitney $U$ test or analysis of variance, as appropriate. Statistical analyses were carried out using the SYSTAT (Evanston, Illinois, USA) statistical package.

\section{Results}

The study group consisted of 22 patients with chronic heart failure aged 62.3 (SEM 2.7) years, with a body mass index of $23.0(0.6)$ $\mathrm{kg} / \mathrm{m}^{2}$ (table 1). There were no significant differences in blood flow between the group with chronic heart failure due to coronary heart disease and those with idiopathic dilated cardiomyopathy (resting blood flow: coronary heart disease $=3.04 \quad(0.33)$, dilated cardiomyopathy $=2.77(0.32)$; maximum blood flow: coronary heart disease $=26.72(2.45)$, dilated 
Scatterplot of serum uric acid concentrations against maximum blood flow in patients with chronic heart failure.

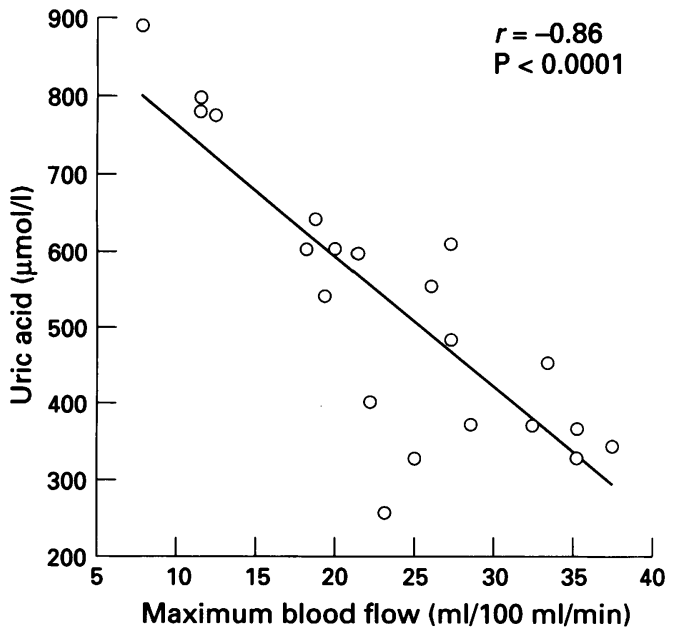

cardiomyopathy $=20 \cdot 49(2 \cdot 51))$. There were no differences in any of the other variables between the group with chronic heart failure due to coronary heart disease and those with idiopathic dilated cardiomyopathy (data not shown).

In univariate correlation analyses, serum uric acid was negatively correlated with maximum blood flow $(r=-0.86, P<0.001)$ (figure), but no significant correlation emerged between serum uric acid and resting blood flow. Left ventricular ejection fraction did not correlate with maximum blood flow $(r=0.27)$. As shown in table 2 , patients in the upper tertile of serum uric acid concentrations had lower maximum blood flow than those in the lowest tertile $(P=0.003)$. In contrast, no differences were detected with respect to resting blood flow with increasing tertiles of uric acid.

In stepwise regression analyses, serum uric acid emerged as the only significant predictor of maximum blood flow (table 3), independently of diuretic dose, age, body mass index, plasma creatinine, fasting glucose and insulin, IVGTT glucose and insulin, insulin sensitivity, exercise time, maximum oxygen uptake, and alcohol intake. In further analyses, aetiology of chronic heart failure failed to enter into stepwise regression models (data not shown). Similar results were obtained when age
Table 3 Results of stepwise multiple regression analysis using maximum blood flow as the dependent variable

\begin{tabular}{lcc}
\hline & $\begin{array}{c}\text { Standardised } \\
\text { coefficient }\end{array}$ & P value \\
\hline Independent variables & -0.83 & $<0.001$ \\
Uric acid & \\
Variables that failed to enter into regression model & \\
Diuretic dose \\
Fasting glucose \\
Incremental glucose area \\
Fasting insulin \\
Incremental insulin area \\
Creatinine \\
Insulin sensitivity index \\
Body mass index \\
Age \\
Alcohol intake \\
Maximum oxygen uptake \\
Exercise time \\
$\mathrm{R}^{2}$ \\
${ }^{\star}$ Entered as frusemide equivalent dose.
\end{tabular}

adjusted values were employed. On stepwise analysis, only IVGTT insulin area emerged as a significant predictor of resting blood flow (standardised coefficient $=-0.43, \quad P=$ $0.027 ; R^{2}=0.64, P=0.0012$ for analysis) (data not shown).

\section{Discussion}

To our knowledge, this is the first report of an association between serum uric acid concentrations and arterial blood flow in patients with chronic heart failure. The hyperuricaemic effects of concurrent diuretic treatment ${ }^{12}$ might reasonably be suspected as the cause of this relation. However, neither diuretic dose nor any other metabolic factor which is known to affect serum uric acid metabolism achieved statistical significance in multivariate regression analyses.

Interestingly, serum uric acid was strongly associated with maximum blood flow, but not with resting blood flow. This suggests that serum uric acid is somehow related to blood flow responses after exercise and ischaemia. In this respect, we have recently shown that in patients with chronic heart failure serum uric acid is inversely related to exercise tolerance and to maximum oxygen uptake during a treadmill exercise test. ${ }^{21}$ This is consistent with reports of increased serum uric acid in various

Table 2 Clinical and metabolic variables of patients with chronic heart failure, grouped according to tertiles of serum uric acid concentrations

\begin{tabular}{|c|c|c|c|c|c|}
\hline & \multicolumn{3}{|l|}{ Tertiles of serum uric acid } & \multicolumn{2}{|c|}{ Pvalue } \\
\hline & 1 & 2 & 3 & $2 v 1$ & $3 v 1$ \\
\hline $\begin{array}{l}\text { Uric acid }(\mu \mathrm{mol} / \mathrm{l}) \\
\text { Age (years) } \\
\text { Body mass index }\left(\mathrm{kg} / \mathrm{m}^{2}\right) \\
\text { Systolic blood pressure }(\mathrm{mm} \mathrm{Hg}) \\
\text { Diastolic blood pressure }(\mathrm{mm} \mathrm{Hg}) \\
\text { Alcohol intake }(7 \mathrm{units} / \mathrm{week}) \\
\text { Creatinine }(\mu \mathrm{mol} / \mathrm{l}) \\
\text { Fasting glucose }(\mathrm{mmol} / \mathrm{l}) \\
\text { IVGTT glucose }(\mathrm{mmol} / \mathrm{min}) \\
\text { Fasting insulin }(\mathrm{pmol} / \mathrm{m}) \\
\text { IVGTT insulin }\left(\mathrm{pmol} / 10^{-4}\right) \\
\text { Insulin sensitivity }\left(10^{5} / \mathrm{min} /[\mathrm{pmol} / \mathrm{l}]\right) \\
\text { Diuretic dose }(\mathrm{mg})^{\star} \\
\text { Resting blood flow }(\mathrm{ml} / 100 \mathrm{ml} / \mathrm{min}) \\
\text { Maximum blood flow }(\mathrm{ml} / 100 \mathrm{ml} / \mathrm{min}) \\
\text { Left ventricular ejection fraction }(\%)\end{array}$ & $\begin{array}{l}339 \cdot 6(15 \cdot 2) \\
55 \cdot 1(5 \cdot 0) \\
22 \cdot 1(2 \cdot 2) \\
108 \cdot 6(4 \cdot 0) \\
68 \cdot 9(3 \cdot 6) \\
19 \cdot 6(3 \cdot 0) \\
100 \cdot 4(3 \cdot 9) \\
5 \cdot 4(0 \cdot 3) \\
497 \cdot 9(56 \cdot 7) \\
20 \cdot 7(-11 \cdot 6,26 \cdot 1) \\
1 \cdot 3(-0 \cdot 5,0 \cdot 8) \\
2 \cdot 01(-1 \cdot 55,2 \cdot 64) \\
51 \cdot 4(14 \cdot 4) \\
2 \cdot 5(0 \cdot 21) \\
31 \cdot 0(2 \cdot 1) \\
27 \cdot 4(5 \cdot 1)\end{array}$ & $\begin{array}{l}500 \cdot 0(26 \cdot 6) \\
64 \cdot 3(3 \cdot 2) \\
24 \cdot 4(1 \cdot 5) \\
118 \cdot 6(7 \cdot 8) \\
69 \cdot 7(2 \cdot 20 \\
3 \cdot 0(1 \cdot 1) \\
121 \cdot 4(10 \cdot 6) \\
5 \cdot 4(0 \cdot 2) \\
564 \cdot 1(46 \cdot 2) \\
62 \cdot 4(-17 \cdot 7,24 \cdot 7) \\
2 \cdot 7(-0 \cdot 1,0 \cdot 2) \\
1 \cdot 99(-1 \cdot 04,1 \cdot 37) \\
82 \cdot 9(9 \cdot 2) \\
3 \cdot 1(0 \cdot 4) \\
26 \cdot 1(2 \cdot 1) \\
19 \cdot 9(7 \cdot 5)\end{array}$ & $\begin{array}{l}711 \cdot 8(40 \cdot 5) \\
67 \cdot 1(4 \cdot 7) \\
22 \cdot 45(0 \cdot 9) \\
102 \cdot 5(8 \cdot 2) \\
62 \cdot 3(5 \cdot 7) \\
5 \cdot 0(2 \cdot 4) \\
160 \cdot 5(19 \cdot 6) \\
7 \cdot 7(1 \cdot 6) \\
743 \cdot 6(130 \cdot 9) \\
47 \cdot 5(-26 \cdot 2,58 \cdot 4) \\
1 \cdot 3(-0 \cdot 7,0 \cdot 1) \\
1 \cdot 39(-1 \cdot 21,2 \cdot 32) \\
135 \cdot 0(25 \cdot 0) \\
3 \cdot 1(0 \cdot 5) \\
15 \cdot 6(2 \cdot 2) \\
15 \cdot 9(2 \cdot 9)\end{array}$ & $\begin{array}{l}\text { NS } \\
\text { NS } \\
\text { NS } \\
\text { NS } \\
\text { NS } \\
\text { NS } \\
\text { NS } \\
\text { NS } \\
0.009 \\
0.025 \\
\text { NS } \\
\text { NS } \\
\text { NS } \\
\text { NS } \\
\text { NS }\end{array}$ & $\begin{array}{l}\text { NS } \\
\text { NS } \\
\text { NS } \\
\text { NS } \\
\text { NS } \\
0.021 \\
\text { NS } \\
\text { NS } \\
\text { NS } \\
\text { NS } \\
\text { NS } \\
0 \cdot 01 \\
\text { NS } \\
0.003 \\
0.049\end{array}$ \\
\hline
\end{tabular}

Results are expressed as mean (SEM), except for insulin concentrations and insulin sensitivity, which are expressed as mean ( - SEM, + SEM).

IVGTT, intravenous glucose tolerance test.

$\star$ Entered as frusemide equivalent dose ( $1 \mathrm{mg}$ bumetanide $=\mathbf{4 0} \mathrm{mg}$ frusemide). 
hypoxic states. ${ }^{22-26}$ Xanthine oxidase activity has been shown to increase during ischaemia and to intensify during reperfusion in coronary endothelial cells. ${ }^{27}$ It is also noteworthy that interruption of regional blood leads to an increase in uric acid production. ${ }^{28}$ Thus failure to meet the tissue demand for oxygen during exercise might explain our observation of an inverse relation between serum uric acid and maximum blood flow in patients with chronic heart failure.

We found no significant association between maximum blood flow and left ventricular ejection fraction. This is consistent with numerous studies highlighting the lack of an association between exercise tolerance and haemodynamic indices of cardiac function in patients with chronic heart failure. ${ }^{29} 30$ While left ventricular ejection fraction did not correlate with serum uric acid on univariate analysis, it was significantly lower in patients in highest tertile of serum uric acid than in those in the lowest tertile. An association between serum uric acid and cardiac function might be expected in view of the relation between the degree of xanthine oxidase inhibition by allopurinol and improvement of postischaemic left ventricular function in isolated hearts subjected to global ischaemia. ${ }^{31}$ Studies in animals have clearly shown that allopurinol has a potent effect on myocardial infarct limitation when given before coronary occlusion. ${ }^{32}$ In addition, allopurinol has also been shown to enhance the recovery of stunned myocardium. ${ }^{33}$ In humans, allopurinol has been shown to exert a dose related protective effect on the myocardium of patients undergoing heart operations..$^{34}$

There is increasing evidence that free radicals play a major role in the impairment of vasomotor control in cardiovascular disorders. The reaction catalysed by xanthine oxidase is an important source of superoxide free radicals. ${ }^{35}$ Inhibition of xanthine oxidase by allopurinol has been shown to improve endothelium dependent vasomotor responses in animals. ${ }^{36-38}$ To our knowledge, no studies have examined the effects of allopurinol on vasomotor control in humans. Our finding of a relation between blood flow at the peak of exercise and serum uric acid concentrations could be related to the deleterious effects of xanthine oxidase derived free radicals on vascular function.

Our group has previously shown that impairment of lower limb blood flow in chronic heart failure is linked to an impairment of both endothelium independent and endothelium dependent mechanisms. ${ }^{39}$ Accumulating evidence suggests that such disturbances are related to the release of nitric oxide. Interestingly, both impaired endothelial release of nitric oxide ${ }^{40}$ and increased activity of xanthine oxidase/dehydrogenase ${ }^{36-38}$ occur in disorders of vasomotion. Moreover, nitric oxide is known to exert a potent dose dependent inhibition of xanthine oxidase/dehydrogenase. ${ }^{4143}$ On the basis that xanthine oxidase is a major source of toxic free radicals, it has been proposed that inactivation of this enzyme by nitric oxide could represent a protective role of nitric oxide in the endothelium. ${ }^{42}$ On the other hand, nitric oxide reacts with vasodilator superoxide ions to yield (non-vasodilator) peroxynitrite. ${ }^{44}$ Thus release of superoxide ions during uric acid production could attenuate the vasodilator effects of nitric oxide ${ }^{45}$ by increasing its conversion to peroxynitrite. This is consistent with the finding that inhibition of xanthine oxidase by allopurinol potentiates nitric oxide mediated vasorelaxation.

In conclusion, we have shown a strong association between serum uric acid concentrations and maximum leg blood flow in patients with chronic heart failure. Whether this association is related to an involvement of xanthine oxidase in the impairment of vascular tone that characterises chronic heart failure remains unresolved. Further studies are needed to determine whether serum uric acid can be used as an index of vascular function in cardiovascular diseases. The possible effects of xanthine oxidase inhibitors on vasomotor responses in patients with chronic heart failure warrant further investigation.

1 Zelis R, Fleim S. Alterations in vasomotor tone in congestive heart failure. Prog Cardiovasc Dis 1968;24:437-59.

2 Sullivan M, Knight J, Higginbotham M, Cobb F. Relation between central and peripheral hemodynamics during exercise in patients with chronic heart failure. Muscle blood flow is reduced with maintenance of arterial perfusion pressure. Circulation 1989;80:769-81.

3 Zelis R, Mason D, Braunwald E. A comparison of the effects of vasodilator stimuli on peripheral resistance vessels in normal subjects and in patients with congestive heart failure. $\mathcal{F}$ Clin Invest 1968;47:960-70.

4 LeJemtel T, Maskin C, Lucido D, Chadwick B. Failure to augment maximal limb blood flow in response to one-leg versus two-leg exercise in patients with severe heart failure. Circulation 1986;74:245-51.

5 Piepoli M, Clark A, Volterrani M, et al. Muscle ergoreflex role in exertional dyspnoea in chronic heart failur patients [abstract]. $\mathcal{F} \mathrm{Am}$ Coll Cardiol 1989;21:480A.

6 Friedl HP, Smith DJ, Till GO, Thomson PD, Louis DS, Ward PA. Ischemia-reperfusion in humans. Appearance of xanthine oxidase activity. Am $\mathcal{f}$ Pathol 1990;136: 491-5.

7 Lowe G, Fowkes F, Dawes J, Donnan P, Lennie S Housley E. Blood viscosity, fibrinogen, and activation of coagulation and leukocytes in peripheral arterial disease and the normal population in the Edinburgh Artery Study. Circulation 1993;87:1915-20.

8 Huizer T, de Jong J, Nelson J, et al. Urate production by human heart. F Mol Cell Cardiol 1989;21:691-5.

9 Snoeckx L, van der Vusse G, Coumans W, Willemsen $P$ Reneman R. Differences in ischaemia tolerance between the postischaemic functional and biochemical recovery of adult and aged hypertrophied hearts. Cardiovasc Res 1993;27:874-81.

10 Lazzarino G, Raatkainen P, Nuutinen M, et al. Myocardia release of malondialdehyde and purine compounds during coronary bypass surgery. Circulation 1994;90:291-7.

11 Swan JW, Walton C, Godsland IF, Clark AL, Coats AJS Oliver MF. Insulin resistance in heart failure. Eur Heart 1994;15:1528-32.

12 Carlsen J, Kober L, Torp-Pedersen C, Johansen P. Relation between dose of bendrofluazide, antihypertensive effect, and adverse biochemical effects. $B M \mathcal{F}$ 1990;300:975-8.

13 Grahame R, Scott J. Clinical survey of 354 patients with gout. Ann Rheum Dis 1970;29:461-8.

14 Facchini F, Chen Y, Hollenbeck C, Reaven G. Relationship between resistance to insulin-mediated glucose uptake, urinary uric acid clearance and plasma uric acid uptake, urinary uric acid clearance and plas

15 Modan M, Halkin H, Karasik A, Lusky A. Elevated serum uric acid-a facet of hyperinsulinaemia. Diabetologia 1987;30:713-18.

16 Volterrani M, Clark A, Ludman P, et al. Predictors of exercise capacity in chronic heart failure. Eur Heart $\mathcal{F} 1994$ 15:801-9.

17 Trinder P. Determination of blood glucose using an oxidase-peroxidase system with non-carcinogenic chromogen. F Clin Path 1969;22:158-61.

18 Albano JDM, Ekins RP, Maritz G, Turner RC. A sensitive, precise radioimmunoassay of serum insulin relying on charcoal separation of bound and free hormone moieties. Acta Endocrinol 1972;70:487-509.

19 Gochman N, Schmitz J. Automated determination of uric acid using a uricase-peroxidase method. Clin Chem 1971; 
17:1154-9.

20 Bergman RN, Ider YZ, Bowden CR, Cobelli C. Quantitative estimation of insulin sensitivity. $A m \mathcal{f}$ Quantitative estimation
Physiol 1979;236:E667-77.

21 Leyva F, Anker S, Swan J, et al. Serum uric acid as an index of impaired oxidative metabolism in chronic heart failure. Eur Heart $\mathcal{F}$ 1997;18:858-65.

22 Braghiroli A, Sacco C, Erbetta M, Ruga V, Donner C. Overnight urinary acid:creatinine ratio for the detection of sleep hypoxemia. Validation study in chronic obstructive pulmonary disease and obstructive sleep apnea before and after treatment with nasal continuous positive airway pressure. Am Rev Respir Dis 1993;148:173-8.

23 Hasday J, Grum C. Nocturnal increase of urinary uric acid:creatinine ratio. A biochemical correlate of sleepassociated hypoxemia. Am Rev Respir Dis 1987;135: 534-8.

24 Porter KB, O'Brien WF, Benoit R. Comparison of cord purine metabolites to maternal and neonatal variables of pypoxia. Obstet Gynecol 1992;79:394-7.

25 Saugstad OD. Hypoxanthine as a measurement of hypoxia. Pediatr Res 1975;9:158-61.

26 Hayabuchi Y, Matsuoka S, Akita H, Kuroda Y. Hyperuricaemia in cyanotic congenital heart disease. Eur $\mathcal{f}$ Pediatr 1993;152:873-6.

27 Ashraf M, Samra Z. Subcellular distribution of xanthine oxidase during cardiac ischaemia and reperfusion: an immunocytochemical study. I Submicrosc Cytol Pathol 1993;25:293-301.

28 Mathru M, Dries DJ, Barnes L, Tonino P, Sukhani R, Rooney MW. Tourniquet-induced exsanguination in patients requiring lower limb surgery. An ischemia-reperfusion model of oxidant and antioxidant metabolism. Anesthesiology 1996;84:14-22.

29 Franciosa J, Park M, Levine T. Lack of correlation between exercise capacity and indexes of resting left ventricular performance in heart failure. Am f Cardiol 1981;47:33-9.

30 Lipkin D, Poole-Wilson P. Symptoms limiting exercise capacity in chronic heart failure. BMF 1986;292:653-5.

31 Grum C, Ketai L, Myers C, Shlafer M. Purine efflux after cardiac ischaemia: relevance to allopurinol cardioprotection. Am ₹ Physiol 1987;252:368-73.

32 Montor S, Thoolen M, Mckin W, Timmermans P. Effect of azapropazone and allopurinol on myocardial infarct size in rats. Eur $\mathcal{F}$ Pharmacol 1987;140:203-7.

33 Bolli R. Oxygen-derived free radicals and postischaemic myocardial dysfunction ("stunned myocardium"). $₹ \mathrm{Am}$
Coll Cardiol 1988;12:239-49.

34 Tabayashi $\mathrm{K}$, Suzuki $\mathrm{Y}$, Nagamine S, Ito $\mathrm{Y}$, Sekino $\mathrm{Y}$, Mohri H. A clinical trial of allopurinol (Zyloric) for myocardial protection. F Thorac Cardiovasc Surg 1991;
101:713-8.

35 Zweier J, Kuppusamy P, Lutty G. Measurement of endothelial cell free radical generation: evidence for a central mechanism of free radical injury in post-ischaemic tissues. Proc Natl Acad Sci USA 1988;85:4046-50.

36 Sobey C, Dalipram R, Wodman O. Allopurinol and amlodipine improve coronary vasodilation after myocardial ischaemia and reperfusion in anaesthetised dogs. $B$ I Pharmacol 1993;108:342-7.

37 Sobey C, Dalipram R, Dusting G, Woodman O. Impaired endothelium-dependent relaxation of dog coronary arteries after myocardial ischaemia and reperfusion: prevention by amlodipine, propranolol and allopurinol. $B r \mathcal{f}$ Pharmacol 1992;105:557-62.

38 Tesfamariam B, Cohen R. Free radicals mediate endothelial cell dysfunction caused by elevated glucose. $A m \mathcal{F}$ Physiol 1992;263:H321-6.

39 Lindsay D, Holdright D, Clarke D, Anand I, Poole-Wilson P, Collins P. Endothelial control of lower limb blood flow in chronic heart failure. Heart 1996;75:469-76.

40 Ramsey M, Goodfellow J, Jones C, Luddington L, Lewis $M$, Henderson A. Endothelial control of arterial distensibility is impaired in chronic heart failure. Circulation 1995;92:3212-19.

41 Fakahori M, Ichimori K, Ishida H, Nakagawa H, Okino H. Nitric oxide reversibly suppresses xanthine oxidase activity. Free Radic Res 1994;21:203-12.

42 Rinaldo J, Clark M, Parinello J, Shepherd V. Nitric oxide inactivates xanthine oxidase dehydrogenase and xanthine oxidase in interferon-gamma-stimulated macrophages. Am $\mathfrak{F}$ Respir Cell Mol Biol 1994;11:625-30.

43 Hassoun P, Yu F, Zulueta J, White A, Lanzillo J. Effect of nitric oxide and cell redox status on the regulation of nitric oxide and cell redox status on the regulation of 1995;268:pL 809-17.

44 Haddad I, Crow J, Hu P, Ye Y, Beckman J, Matalon S. Concurrent generation of nitric oxide and superoxide damages surfactant protein A. Am $\mathcal{F}$ Physiol 1994;267: pL242-9.

45 Miyamoto $\mathrm{Y}$, Akaike T, Yoshida $\mathrm{M}$, Goto $\mathrm{S}$, Horie $\mathrm{H}$, Maeda H. Potentiation of nitric oxide-mediated vasorelaxation by xanthine oxidase inhibitors. Proc Soc Exp Biol Med 1996;211:366-73. 